\title{
Length-Weight Relationship of Pompano Trachinotus Ovatus cultured in Brunei
}

\author{
Xilei Liu ${ }^{1,2 *}$, Ming Liu ${ }^{1,2}$, Siti Nurafiqah Basyirah Binti Hussin ${ }^{2}$ \\ ${ }^{1}$ Guangxi Hiseaton Foods Co., Ltd, Fangchenggang, 538021, P.R. China \\ ${ }^{2}$ Hiseaton Fisheries (B) Sdn Bhd, Brunei, BT2728, Brunei Darussalam
}

*Corresponding Author: Xilei Liu, Guangxi Hiseaton Foods Co., Ltd, Fangchenggang, 538021, P.R. China

\begin{abstract}
Length-weight relationship of golden pompano, Trachinotus ovatus (Linnaeus 1758) cultured in sea cages located in Brunei were examined in the present study. A total of 540 fish were collected from sea cages located in Pilongpong harboraging from 2 months to 10 years old. The length-weight relationship of young golden pompano can be expressed as $W=0.1901 \times$ L1.9826. While the length-weight relationship of golden pompano brood stocks can be expressed as $W=0.197 \times$ L2.4282. Results from present study suggested that the growth of golden pompano follow negative allometric trend and the body appearance of golden pompano reared in sea cages of Pilongpong harbor under semi-intensive condition were not differing from their counterparts that lived in natural condition.
\end{abstract}

Keywords: Length-weight relationship, golden pompano Trachinotus ovatus, Growth, sea cage, allometry.

Length-weight relationships have been well implicated in fisheries science and population dynamics (Erzini, 1994). In practices, length-weight relationship can be used to estimate weight from length for individual fish, fish length classes, and the standing-crop biomass when the length-frequency distributing is known (Goncalves et al., 1997; Petrakis and Stergiou, 1995). Apart from field practices, length-weight relationship has also been used to calculate the condition index of selected species as well as to compare the life history and morphological difference between populations from different regions (Nie et al., 2013; Petrakis and Stergiou, 1995). In aquaculture, length-weight relationships can also be used to assess the growth and population parameters of fish cultured in open sea rearing systems for selected species (Philipose et al., 2013).

Golden pompano Trachinotus ovatus (Linnaeus 1758) belongs to the family of Carangidae, is distributing in Indian Ocean, Indonesia, Australia, China, Japan, tropical area of America, temperate zone of Mediterranean Sea, and western coast of Africa (Chen et al., 2007). In China, wild golden pompano can be found in Yellow Sea, East China Sea and South China Sea (Ou and Li, 2005). Due to the market demand, cultured of golden pompano increased dramatically since 2016in Brunei. While artificial breeding of this specie in Brunei is not established in commercial scales. Because of the fast growth and high flesh quality, golden pompano is being considered as a good candidate for sea cages culture in Southeast Asia. In term of production feasibility, cage culture has made the large-scale production of golden pompano become possible and has been considered as the most economical method to rear golden pompano.

In this study, length-weight relationship of golden pompano was estimated in sea cages in Pilongpong harbor, Brunei. The relationships estimated in the present study will complement the data provided by previous study in specie. To our best knowledge, data presented in this experiment was the first length-weight relationship estimation of golden pompano in sea cages rearing system in Southeast Asia.

In the present study, length-weight relationship of golden pompano was estimated from one site located in Pilongpong harbor, Brunei. According to the farms' record, all the fish sampled in the present study were artificially produced. The growth data were collected during the routine cage transfers, between May 2018 and March 2019. Water samples were collected from floating sea cages 
culture site on daily intervals, testing parameters including temperature, $\mathrm{pH}$, dissolved oxygen, and salinity.

The ages of young golden pompano were between 2-months and 3-months old, while the brood stocks were between 8 years and 10 years old. The size of floating sea cage used for grow out culture was 4 $\times 4 \times 4 \mathrm{~m}$ (length $\times$ width $\times$ height), and brood stocks were kept in $4 \times 6 \times 4 \mathrm{~m}$ (length $\times$ width $\times$ height) sea cages. The stocking density used in grow out culture (around $500 \mathrm{~g}$ per fish) was 500 fish/cage, while brood stocks were stocked at $40 \mathrm{fish} / \mathrm{cages}$. Fish from grow out system were fed 3times/day with floating pellets at 5-8\% of the total biomass. Brood stocks were fed one time per day with fresh chopped fish and squids at $7 \%$ of the total biomass.

Before being weighed and measured, fish were anaesthetized with Aquis-S (Aquis-S, New Zealand) using the recommended dose according to the manufacturer's instructions. The lengths of fish were measured using flexible rule (accurate to $\pm 0.1 \mathrm{~mm}$ ) and wet weights were obtained by using an electronic balance (accurate to $\pm 0.1 \mathrm{~g}$ ). Total length was taken from the tip of the jaw to the end of the caudal fin tip.

The relationship between total length (L) and wet weigh (W) were calculated by the power regression $W=a \times L^{b}$ (PASW Statistics 20.0) where $L$ was the total length $(\mathrm{cm})$ and $W$ was the wet weight $(\mathrm{g})$. The association degree between $L$ and $W$ was calculated by the determination coefficient $\left(\mathrm{R}^{2}\right)$. Values of the exponent $b$ provide information on fish growth. When $b=3$, the increase in weight was isometric. When the value of $b$ was $>3$, the weight increase was allometric (positive allometric if $b>$ 3 , negative allometric if $b<3$ ).

The water quality recorded at sampling sites was within the optimum range for pompano culture. Temperature ranged from $25.37 \pm 0.32^{\circ} \mathrm{C}$ to $29.98 \pm 0.65^{\circ} \mathrm{C}$ with a mean value of $27.13^{\circ} \mathrm{C}$, dissolved oxygen level ranged from 5.07-7.19 $\mathrm{mgL}^{-1}$ (mean $6.43 \mathrm{mgL}^{-1}$ ), salinity were between $28-33 \%$ (mean $30.15 \%$ ), and $\mathrm{pH}$ were between 7.9 and 8.3 .

Total length of pre sexually mature fish collected in the present study varied from $4.71 \mathrm{~cm}$ to 11.94 $\mathrm{cm}$ with the wet weight ranging from $5.32 \mathrm{~g}$ to $28.38 \mathrm{~g}$ (Fig. 1). The total lengths of brood stocks obtained from this study were ranging from $77.28 \mathrm{~cm}$ to $112 \mathrm{~cm}$ and the wet weight was between $8330 \mathrm{~g}$ and $17850 \mathrm{~g}$, respectively (Fig. 2). The relationship between fish length and wet weight of pre matured fish was derived as $W=0.1901 \times L^{1.9826}\left(r^{2}=0.8991, n=500\right.$, Fig. 1$), a=0.1901$, and $b=$ 1.9826 while the length-weight relationship of brood stocks obtained in this study can be expressed as $W=0.197 \times L^{2.4282}\left(r^{2}=0.6625, n=40\right.$, Fig. 2$), a=0.197$, and $b=2.4282$. The value of $b<3$, obtained in the present study indicates that the growth of golden pompano reared in floating sea cages follows negative allometric trend. Similar results have been reported in cage cultured golden pompano in Hainan, P.R. China (Zhang et al., 2016). Results from the present study are consistent with the data collected from wild caught pompano. The growth of pompano collected from both North-eastern Atlantic and Western Mediterranean follow negative allometric trend though the $b$ value was slight difference (Morato et al., 2001; Morey et al., 2003).

The $b$ value obtained from Western Mediterranean ( $b=2.9668$,Morey et al., 2003) was greater than the value obtained from North-eastern Atlantic $(b=2.832$,Morato et al., 2001) and our present study $(b=1.9826$ (young fish) \& 2.4282 (brood stocks)). The observed difference could be caused by external factors such as geographic difference, sampling procedure, namely sample size, and length range. Since the sample amount in our study was reasonable and can cover large size range, suggesting that the differences in slope could reflect the influence of differences in environmental or habitat factors. For instance, differences in water thermal regime (Jobling, 1997), food availability (Mommsen, 1998) are known to influence fish grow. Furthermore, the smaller $b$ value obtained in the present study may be caused by human practices (such as feeding protocol, and feeding regime) since all the samples collected in the present study were artificial breed and reared fish. The body appearance of $T$. ovatus reared in sea cages in semi-intensive condition was not differing from their counterparts that lived in natural condition. Results from the present study can be used for assessing the growth and population parameters of golden pompano in sea cage culture system. However, for more precise weight estimations through length-weight estimation, it is advisable to make justification by using local values. 


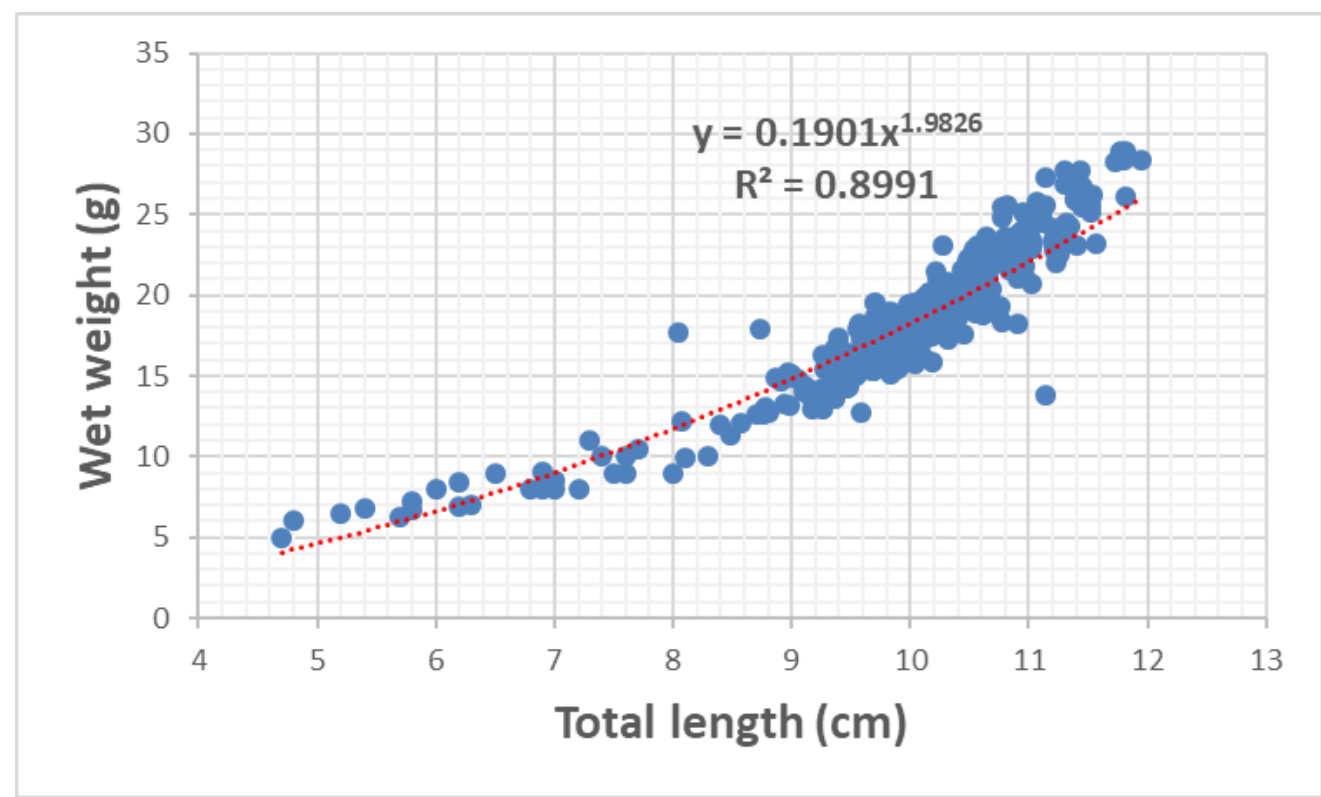

Fig1. Length-weight relationship of Trachinotus ovatus cultured in floating sea cage, $n=500$.

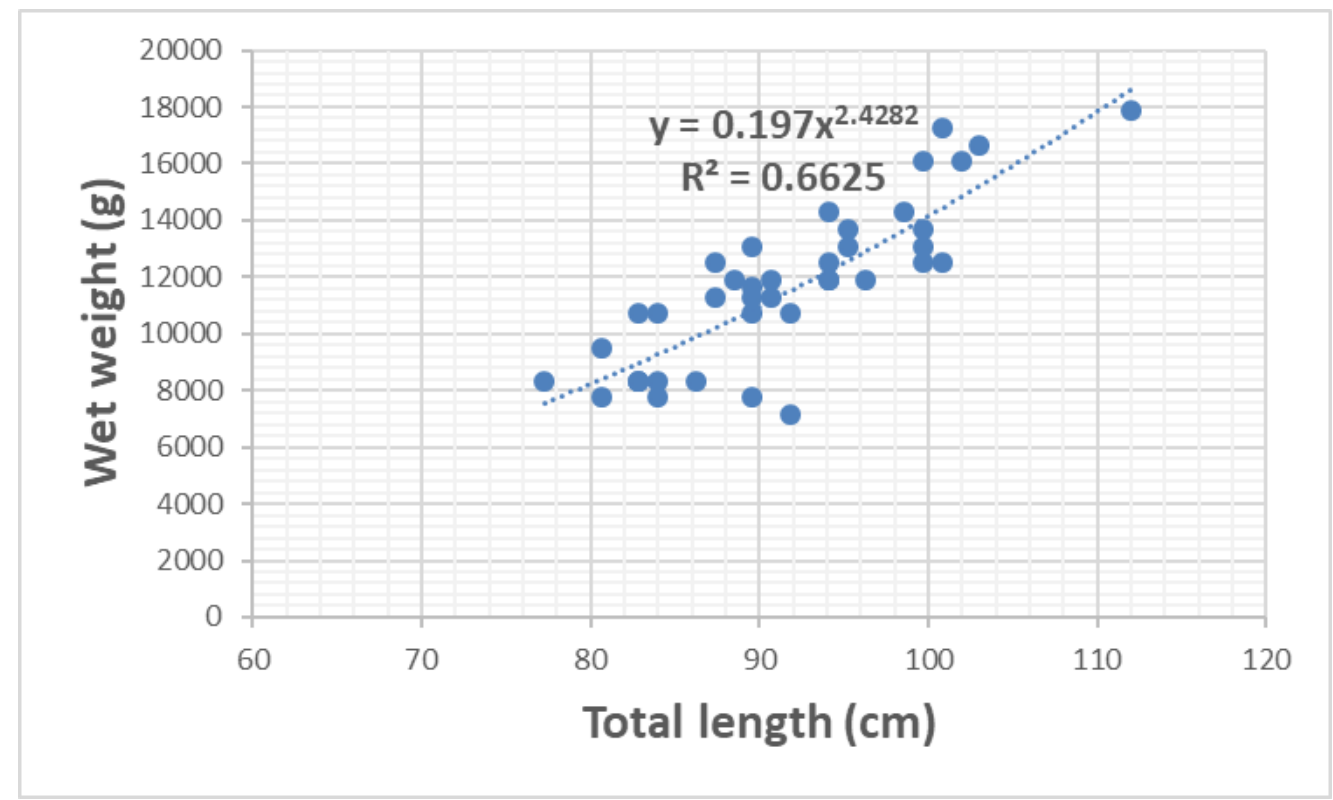

Fig2. Length-weight relationship of Trachinotus ovatus brood stocks cultured in Brunei, $n=40$.

\section{ACKNOWLEDGMENT}

This study was founded by Guangxi Innovation Driven Development Special Fund Project [Guike AA18242031].

\section{REFERENCES}

[1] Chen, W. Z., Xu, D. S., Wang, D. Q., Zheng, Y. M., Yu, W., Qiu, G. Y. and Li, Y. Y. 2007. Study on the spawning and hatchnique for Trachinotus ovatus. Journal of oceanography in Taiwan Strait, 26: 435-442 (Chinese journal with English abstract).

[2] Erzini, K. 1994. An empirical study of variability in length at age of marine fishes. J. Appl. Ichthyol., 10: $17-41$.

[3] Goncalves, J. M. S., Bentes, L., Lino, P. G., Ribeiro, J., Canario, A. V. M. and Erizini, K. 1997. Weightlength relationships for selected fish species of the small-scale demersal fisheries of the south and southwest coast of Portugal. Fish. Res., 30: 253-256.

[4] Jobling, M. 1997. Temperature and growth: modulation of growth rate via temperature change. In: Wood, C. M. and Mcdonald, D. G. (Eds.), Gloishbal Warming: Implications for freshwater and marine f, Cambridge University Press, Cambridge, p. 225-253.

[5] Mommsen, T. P. 1998. Growth and metabolism. In: Evans, D. H. (Ed.) CRC Press, New York, p. 65-97. 
[6] Morato, T., Afonso, P., Lourinho, P., Barreiros, J. P., Santos, R. S. and Nash, R. D. M. 2001. Length-weight relationships for 21 coastal fish species of the Azores, north-eastern Atlantic. Fish. Res., 50: 297-302.

[7] Morey, G., Moranta, J., Massuti, E., Grau, A., Linde, M., Riera, F. and Morales-Nin, B. 2003. Weightlength relationships of littoral to lower slope fishes from the western Mediterranean. Fish. Res., 62: 89-96.

[8] Nie, Z., Wu, H., Wei, J., Zhang, X. and Ma, Z. 2013. Length-weight relationship and morphological studies in Kashgarian loach Triplophysa yarkandensis (Day, 1877) from the Tarim River, Tarim River Basin, North-West China. Indian J. Fish., 60: 15-19.

[9] Ou, Y. and Li, J. E. 2005. Early embryonic development in Trachinotus ovatus. J. Fish. Sci. China, 12: 786-788 (Chinese Journal with English Abstract).

[10] Petrakis, G. and Stergiou, K. I. 1995. Weight-length relationships for 33 fish species in Greek water. Fish. Res., 21: 465-469.

[11] Philipose, K. K., Divu, D., Krupesha Sharma, S. R., Vaidya, N. G., Sadhu, N. and Dube, P. N. 2013. Length-weight relationship of Asian sea bass, Lates calcarifer (Bloch) reared in open sea floating cages. Indian J. Fish., 60: 139-140.

[12] Zhang, N., Yang, Q., Ma, Z., Cheng D., Guo H. 2016. Length-weight relationship, condition factor, gonads index, and visceral mass index of golden pompano (Trachinotus ovatus) (Pisces: Carangidae) from South China Sea. International Journal of Innovative Studies in Aquatic Biology and Fisheries, 2(2): 39-42.

Citation: Xilei Liu, et.al, "Length-Weight Relationship of Pompano Trachinotus Ovatus cultured in Brunei". International Journal of Innovative Studies in Aquatic Biology and Fisheries, 5(4), pp.32-35 .http://dx.doi.org/10.20431/2454-7670.0504006

Copyright: () 2019 Authors. This is an open-access article distributed under the terms of the Creative Commons Attribution License, which permits unrestricted use, distribution, and reproduction in any medium, provided the original author and source are credited. 